\title{
Gambaran Motivasi Menjadi Dokter pada Mahasiswa Tahun Pertama Fakultas Kedokteran Universitas Padjadjaran
}

\author{
Sari Puspa Dewi, ${ }^{1}$ Insi Farisa Desy Arya, ${ }^{1}$ Achadiyani, ${ }^{2}$ Tri Hanggono Achmad, ${ }^{3}$
}

\begin{abstract}
${ }^{1}$ Departemen Ilmu Kesehatan Masyarakat,Fakultas Kedokteran Universitas Padjadjaran ${ }^{2}$ Departemen Anatomi dan Biologi Sel, Fakultas Kedokteran Universitas Padjadjaran ${ }^{3}$ Departemen Biokimia dan Biologi Molekuler, Fakultas Kedokteran Universitas Padjadjaran
\end{abstract}

\begin{abstract}
Abstrak
Dokter adalah profesi yang luhur dan dibutuhkan untuk memberikan pelayanan kesehatan kepada masyarakat. Pendidikan kedokteran merupakan pendidikan yang tidak mudah dan membutuhkan motivasi yang kuat untuk menyelesaikannya. Motivasi internal maupun eksternal telah diketahui dapat memengaruhi proses belajar maupun hasil belajar mahasiswa. Dengan mengetahui motivasi mahasiswa maka program studi dapat merancang kegiatan pembelajaran yang dapat meningkatkan motivasi mahasiswa. Penelitian ini bertujuan untuk mengetahui motivasi mahasiswa kedokteran memilih pendidikan dokter dan persepsinya terhadap profesi dokter. Penelitian ini merupakan penelitian kualitatif dengan metode fenomenologi. Seluruh mahasiswa yang masuk tahun 2014, pada bulan pertamanya ditugaskan menuliskan motivasi memilih program pendidikan dokter. Esai tersebut lalu dianalisis untuk mendapatkan kesamaan tema. Seluruh mahasiswa sebanyak 281 orang (209 perempuan, 72 laki-laki) menyatakan bahwa motivasi menjadi dokter terutama adalah untuk menolong dan menjaga kesehatan masyarakat. Motivasi lain adalah ingin mempelajari tubuh manusia lebih mendalam. Yang lain menyatakan faktor agama dan dorongan keluarga. Hampir semua mahasiswa memandang profesi kedokteran adalah profesi yang selalu dibutuhkan. Beberapa mahasiswa memandang profesi dokter masih menjanjikan kesejahteraan secara finansial. Data ini menunjukkan bahwa mahasiswa tahun pertama masih memiliki motivasi yang luhur untuk menjadi dokter. Hal ini akan dapat membantu mereka dalam menempuh pendidikan. Penelitian lanjut perlu dilakukan untuk mengetahui perubahan motivasi mereka setelah lulus dokter.
\end{abstract}

Kata kunci: Motivasi, mahasiswa, profesi dokter

\section{Overview of Motivation to Become a Medical Profession in 1st Year Medical Students}

\begin{abstract}
Medical profession is a noble profession and needed to provide medical services to the community. Study in medicine is not easy and requires strong motivation to accomplish it. Motivation is known to influence learning and academic performance. By knowing students' motivation and their perception of medical profession, the educational program can be designed to strengthen their learning process. The objective of this research was to describe first year medical students' motivation for choosing medical program and their perception of medical profession. The methodology used is qualitative method using phenomenology. All students' class 2014 were assigned to write their motivation for choosing medical program. The essay were analysed to search for common themes. All 281 students (209 female and 72 male) stated that their motivation for choosing medical program and become a doctor were to help others in need and maintaining the health of people. Other theme was to learn in-depth of human body. Other stated that religion factor and supported by family, especially mother were their motivation. Most of the students viewed this profession was always be needed and become a doctor is a life-long learning. Few students mentioned medical profession as a wellness profession. This study searched for motivation of the first year medical students, which are noble and generous. Further research is needed to examine whether their motivation and perception after graduate still remains.
\end{abstract}

Key word: Become a doctor, motivation, student

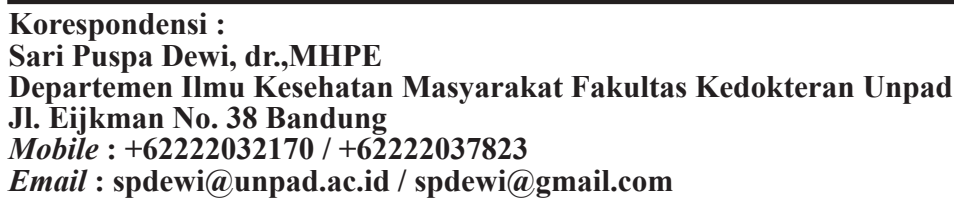




\section{Pendahuluan}

Pendidikan kedokteran merupakan proses pendidikan yang tidak mudah dan membutuhkan konsentrasi dan kemauan yang kuat untuk dapat menyelesaikan semua tahap pendidikannya. ${ }^{1}$ Untuk itu maka mahasiswa harus memiliki motivasi yang kuat untuk menjadi dokter. Motivasi diketahui merupakan aspek yang mendorong seseorang untuk melakukan sesuatu. ${ }^{2}$ Dengan motivasi yang kuat maka mahasiswa kedokteran dapat menyelesaikan pendidikan kedokteran dan bersedia ditempatkan dimana pun untuk bekerja sesuai kebutuhan masyarakat. Pada yudisium mahasiswa tahun pertama Fakultas Kedokteran Universitas Padjadjaran (3) tahun akademik 2013/2014 didapatkan 13 orang mahasiswa tidak dapat melanjutkan pendidikan ke tahun kedua karena memiliki Indeks Prestasi Kumulatif (IPK) yang kurang dari 2,00. Setelah dianalisis lebih lanjut diketahui $80 \%$ mahasiswa tersebut pada awalnya memang tidak ingin menjadi dokter ${ }^{3}$.

Motivasi merupakan salah satu faktor yang memengaruhi seseorang untuk berbuat sesuatu termasuk belajar. Pada akhirnya motivasi juga memengaruhi hasil pembelajarannya, termasuk pilihan profesi dokter ataupun dokter spesialis serta kemauan untuk melanjutkan pendidikan di bidang kedokteran. Motivasi dipengaruhi oleh usia, jenis kelamin, etnik, status sosioekonomik, kepribadian, lama dan kurikulum pada pendidikan kedokteran yang ditempuh, dukungan dari dosen maupun teman. Semua faktor ini tidak dapat dimanipulasi oleh perancang pendidikan kedokteran ${ }^{4}$.

Pendidikan kedokteran saat ini dikembangkan dengan menerapkan berbagai prinsip pendidikan orang dewasa. Model pendidikan ini membutuhkan kemampuan belajar mandiri, belajar dari pengalaman yang pernah dialaminya, lebih suka pembelajaran yang berkaitan dengan kehidupannya, lebih tertarik untuk menyelesaikan masalah, serta lebih kuat dorongan dari motivasi internal untuk belajar daripada motivasi eksternal. ${ }^{5}$ Motivasi juga berkaitan dengan persepsi seseorang terhadap suatu hal. Dengan persepsi yang positif maka dapat memperkuat motivasinya untuk mencapai sesuatu atau menyelesaikan tugasnya. Penelitian oleh Kusurkar (2012) menyatakan bahwa motivasi intrinsik secara signifikan akan memperkuat strategi pembelajaran untuk "meaningful learning", upaya belajar yang lebih keras dan pada akhirnya akan menghasilkan nilai akademik yang baik ${ }^{6}$.

Proses pembelajaran selama ini terdiri dari tiga dimensi yaitu kognitif (apa yang dipelajari), afektif atau motivasional (mengapa belajar) dan regulasi metakognitif (bagaimana cara belajar). Dimensi afektif termasuk bagaimana mengatasi (coping) perasaan yang timbul selama pembelajaran dan mungkin memengaruhi kemajuan belajar seseorang, yang salah satunya adalah aspek motivasi. ${ }^{7}$ Kemajuan perkembangan ilmu pendidikan saat ini telah mendorong pengelola institusi pendidikan untuk dapat mengembangkan program pendidikan yang memerhatikan motivasi mahasiswanya sehingga mahasiswa dapat menyelesaikan pendidikan dengan baik dan bekerja sesuai kompetensinya serta memenuhi kebutuhan masyarakat. ${ }^{8}$

Dengan mengetahui motivasi mahasiswa tersebut menjadi dokter, apakah internal (berasal dari keinginan sendiri untuk belajar) atau eksternal (berasal dari dorongan luar seperti keluarga, lingkungan atau finansial) ${ }^{9}$ maka pengelola studi dapat merancang pendidikan yang dapat memperkuat motivasi tersebut sehingga model pendidikan orang dewasa yang dijalankan dapat terlaksana dengan baik serta dapat dihasilkan dokter yang sesuai harapan masyarakat. Selain itu dengan mengetahui persepsi mahasiswa terhadap profesi dokter akan memberikan informasi kepada pengelola program studi untuk dapat mengembangkan program.

\section{Metode}

Subjek penelitian ini adalah mahasiswa Fakultas Kedokteran Universitas Padjadjaran angkatan 2014 berjumlah 281 orang, terdiri dari 209 orang perempuan dan 72 orang laki-laki. Penelitian ini adalah penelitian deskriprif kualitatif dengan pendekatan fenomenologi. Seluruh subjek penelitian diminta untuk menjawab 2 (dua) pertanyaan yang diajukan pada awal mulai tahun akademik pertama, 1) apa yang memotivasi mereka untuk menjadi seorang dokter, dan 2) apa persepsi mereka terhadap profesi dokter. Jawaban ditulis dalam 3-5 kalimat utama. Esai yang dikumpulkan dianalisis dengan menghilangkan data informasi subjek untuk memastikan konfidensialitas responden. Analisis dilakukan untuk melihat kesamaan tema dari data yang masuk. Dilakukan identifikasi terhadap kalimat utama, selanjutnya dilakukan pemberian kode serta mengkategorikannya menjadi tema umum. Selanjutnya para peneliti mendiskusikan tema umum yang disampaikan dan memodifikasi sampai konsensus tercapai.

\section{Hasil}

Dari 281 mahasiswa PSK angkatan 2014, 
seluruh mahasiswa (100\%) menyerahkan esai.

Tabel. 1 Motivasi Mahasiswa Kedokteran untuk Menjadi Dokter

\begin{tabular}{l}
\hline Tema Umum dan Kalimat Utama \\
\hline 1) Agar dapat menolong orang yang sedang \\
kesakitan, \\
"Saya sangat ingin dapat menolong orang lain da \\
nmemberikan kemanfaatan bagi orang yang \\
sedang sakit. Saya senang melihat senyum di \\
wajah orang yang sudah saya tolong."
\end{tabular}

2) Untuk dapat terlibat dalam menjaga kesehatan masyarakat Indonesia,

"Saya ingin menjadi agen di bidang kesehatan yang terlibat dalam promosi, pencegahan dan pengobatan penyakit. Dengan menjadi dokter saya dapat terlibat dalam pengembangan system kesehatan di Indonesia. Saya dapat meningkatkan kesehatan masyarakat".

3) Pengaruh dari keluarga, terutama ibu

"Saya mau membuat orang tua saya bangga. Di keluarga saya belum ada seorang dokter pun. Ibu saya mengharapkan saya dapat menjadi dokter sehingga dapat menolong keluarga jika ada yang sakit"

4) Alasan keagamaan, terutama Islam

"Denga menjadi dokter, saya menjalankan perintah Allah. Saya dapat lebih mengena lciptaan-Nya dan membuat saya lebih mengerti Islam. Hal ini akan memperkuat keimanan saya"

5) Karier masa depan yang baik

"Dokter adalah profesi yang aman dan paling sukses dan terjamin kedepannya".

6) Profesi dokter akan memberikan kesejahteraan finansial

"Sayamaumengumpulkanuangdanmengembangkan pusat "penelitian dan menemukan obat yang baru."

7) Pengalaman menghadapi kematian keluarga terdekat

"Nenek saya dioperasi berat beberapa tahun yang lalu. Ibu saya mengharapkan dengan menjadi dokter maka yang akan mengoperasi keluarga kami adalah saya."

Pada Tabel 1 dicantumkan tema umum tentang motivasi untuk menjadi dokter. Baik mahasiswa dengan warga Negara Indonesia (233 orang) maupun bukan warga Negara Indonesia (48 orang) menghasilkan tema yang sama, begitu juga tidak ada perbedaan antara jawaban antara laki-laki maupun perempuan. Dalam hal persepsi mahasiswa terhadap profesi dokter, seluruh mahasiswa menganggap profesi dokter adalah profesi yang mulia, memiliki kemampuan untuk terlibat dalam pemeliharaan kesehatan orang lain serta profesi yang dapat menunjukkan kesuksesan (Tabel 2).

Tabel. 2 Persepsi Mahasiswa Terhadap Profesi Dokter

\begin{tabular}{l}
\hline Tema Umum dan Kalimat Utama \\
\hline 1) Profesi dokter adalah profesi yang mulia \\
"Profesi dokter adala hprofesi yang mulia dan \\
dapat memberikan manfaat bagi orang lain." \\
2) Profesi dokter dapat terlibat dalam \\
pemeliharaan kesehatan masyarakat \\
"Seorang dokter dapat membuat perubahan dan \\
menggunakan kemampuan untuk menolong dan \\
memelihatan kesehatan orang lain" \\
3) Profesi dokter menunjukkan kesuksesan \\
dalam hidup \\
"Seorang dokter adalah seorang yang sukses"
\end{tabular}

\section{Pembahasan}

Penelitian ini bermaksud mengetahui motivasi mahasiswa tahun pertama FK Unpad untuk menjadi dokter serta mengetahui persepsinya terhadap dokter. Mahasiswa menyatakan bahwa motivasi untuk menjadi dokter karena keinginan untuk menolong orang lain yang sedang kesakitan serta untuk dapat terlibat dalam pemeliharaan kesehatan masyarakat Indonesia. Motivasi lain adalah karena pengaruh dari ibu, dasar keagamaan dan demi memiliki karier dan kesejahteraan finansial yang lebih baik.

Kusurkar dkk menyatakan bahwa tingkat dan tipe motivasi mahasiswa merupakan determinan utama yang lebih memengaruhi hasil pembelajaran daripada metode pembelajaran sehingga perlu diperhatikan dalam pengembangan kurikulum program studi. Motivasi menentukan pikiran dan tindakan seseorang. Motivasi memengaruhi mengapa suatu perilaku diawali, terus dilakukan ataupun dihentikan maupun pilihan yang ditetapkan. Pada pendidikan kedokteran agar seseorang dapat menjadi dokter yang baik maka diperlukan motivasi untuk dapat belajar secara mendalam (deep learning), capaian kompetensi dan hasil belajar yang baik, serta kemauan untuk selalu belajar.?

Pada pendidikan yang menerapkan student- 
centered, problem-based, integrated teaching, outcome-based, and community-based, titik berat pembelajaran adalah pada proses kognitif maupun metakognitif mahasiswa, sedangkan motivasi tidak begitu diperhatikan. Untuk itu maka motivasi seorang mahasiswa untuk belajar merupakan salah satu penentu keberhasilannya. ${ }^{7}$ Dengan penerapan kurikulum berbasis kompetensi (KBK) di Indonesia termasuk di FK Unpad maka seorang mahasiswa yang memiliki motivasi untuk belajar memiliki kemungkinan untuk berhasil dalam belajarnya.

Mahasiswa kedokteran sudah dikenalkan berbagai ilmu dan praktik kedokteran dasar maupun klinik sejak dari tahun pertama memasuki program studi kedokteran. Misalnya pada Program Sarjana Kedokteran FK Unpad, pada semester pertama mahasiswa sudah dikenalkan dengan permasalahan pada pasien individu maupun masyarakat ${ }^{10}$. Dengan beban belajar seperti ini maka mahasiswa yang tidak memiliki motivasi yang kuat akan mengalami kesulitan belajar, yang apabila hal ini terus dibiarkan akan dapat menghambat pembelajaran mahasiswa. Nilai yang tidak baik akan semakin memperburuk motivasinya sehingga mahasiswa cenderung menarik diri yang pada akhirnya akan menyebabkan kegagalannya dalam belajar ${ }^{11}$. Penelitian ini dilakukan pada semua mahasiswa tahun pertama yang merupakan lulusan Sekolah Menengah Atas. Dari data yang terkumpul $100 \%$ mahasiswa menjawab pertanyaan setelah ditugaskan oleh Dekan dan Ketua Progarm Studi. Instruksi yang diminta adalah memberikan 3-5 kalimat saja, akan tetapi sebagian besar mahasiswa menjawab sampai dengan 1 halaman kertas. Hal ini menunjukkan motivasi instrinsik yang baik karena tidak ada reward bagi mahasiswa yang mengumpulkan maupun punishment bagi mahasiswa yang tidak mengumpulkan.

Di Indonesia, mahasiswa kedokteran merupakan lulusan SMA tanpa melewati pendidikan antara sebelum masuk perguruan tinggi. Rerata usia masuk kedokteran adalah 1617 tahun. Motivasi pada mahasiswa kedokteran tertinggi pada usia 18-24 tahun lalu setelah itu tetap atau semakin menjadi menurun. Mahasiswa yang telah melewati pendidikan awal sebelum masuk kedokteran (pre-medical) memiliki maturitas yang baik sehingga memiliki motivasi yang lebih baik. Usia dan kematangan atau maturitas diketahui memengaruhi motivasi yang pada akhirnya memengaruhi performa dalam pendidikan ${ }^{12}$. Hal ini mungkin karena mereka yang lebih matang dalam keperibadian dan usia memiliki motivasi yang lebih kuat untuk menjadi dokter. Faktor lain yang diketahui memengaruhi motivasi adalah gender. Mahasiswa perempuan memiliki motivasi yang lebih tinggi dalam belajar sehingga menunjukkan performa yang lebih baik daripada mahasiswa laki-laki ${ }^{12}$. Saat ini mahasiswa PSK FK Unpad mencapai 75\% berjenis kelamin perempuan. Walaupun ini belum ada penjelasan ilmiahnya, akan tetapi diperkirakan perkembangan otak perempuan yang lebih awal daripadalaki-lakimemengaruhihalini. Mahasiswa perempuan memiliki motivasi instrinsik yang lebih besar dari pada motivasi eksternal ${ }^{12}$. Pada penelitian ini tidak ada perbedaan jawaban pada mahasiswa perempuan maupun laki-laki.

Dari tema utama yang didapat, tema pertama, kedua dan kelima merupakan motivasi yang terkait dengan motivasi instrinsik. Motivasi instrinsik adalah tipe motivasi yang diharapkan timbul dari diri sendiri seseorang yang mendorongnya untuk melakukan berbagai aktivitas termasuk belajar. Sebagai kebalikannya adalah motivasi eksternal yaitu dorongan dari luar seperti hadiah, hukuman atau melakukan untuk orang lain?. Motivasi mahasiswa untuk dapat menolong orang lain sesuai dengan tujuan yang diharapkan dari seorang dokter. Kesenangan dalam melihat orang lain yang sebelumnya sakit lalu menjadi sembuh merupakan fitrah seorang dokter. Penelitian ini sejalan dengan penelitian sebelumya mahasiswa tahun pertama belum memahami secara utuh peran seorang dokter. Pada mahasiswa tahun pertama pemahaman tentang profesi dokter adalah pada aspek sosial seorang dokter, sebagian mahasiswa belum menyadari peran berat seorang dokter termasuk jam kerjanya yang sangat panjang. Persepsi yang ada ini belum diketahui apakah memiliki pengaruh terhadap motivasi seorang mahasiswa kedokteran.

Alasan untuk membantu orang lain maupun terlibat dalam sistem kesehatan merupakan alasan klasik dan paling banyak disebutkan mahasiswa kedokteran pada waktu ditanya dalam wawancara penerimaan mahasiswa. Adanya motivasi yang terkait keagamaan merupakan tema lain yang merupakan aspek yang spesifik untuk di Indonesia. Jumlah penduduk beragama Islam di Indonesia merupakan yang terbanyak di dunia.Tampaknya hal ini memengaruhi motivasi mahasiswa ini untuk menjadi dokter.

Tema terkait dorongan orang tua dan harapan mendapatkan kehidupan yang lebih baik termasuk ke dalam motivasi eksternal. Dengan menjadi seorang dokter maka mahasiswa tersebut dapat membahagiakan keluarganya terutama ibu. Dorongan seorang ibu di Indonesia, yang sangat kuat maternalistik tampaknya turut memengaruhi jawaban ini.

Seorang dokter masih dipandang oleh masyarakat sebagai orang yang terpandang dan memiliki kesuksesan finansial yang lebih 
dibandingkan profesi yang lain. Hal ini juga yang menjadi motivasi mahasiswa untuk menjadi seorang dokter. Dengan motivasi seperti ini, jika ternyata harapan yang diperoleh tidak sesuai dengan kenyataannya maka dokter tersebut tidak akan mau untuk ditempatkan di seluruh Indonesia, padahal kebutuhan dokter terbanyak adalah di daerah Indonesia bagian Tengah dan Timur yang secarasaranadan prasaranabelumtersedialengkap.

Penelitian dari Wilkinson menemukan bahwa karakteristik mahasiswa kedokteran berkaitan dengan masa studi. Salah satu karateristik tersebut adalah gender. Perbedaan antara motivasi pada perempuan dan laki-laki akan memengaruhi juga performa selama pendidikan juga performanya setelah menjadi dokter ${ }^{13}$.

Aspek lain yang dinilai pada penelitian ini adalah persepsi mahasiswa terhadap profesi dokter saat ini. Dari data yang didapatkan tampak mahasiswa memiliki persepsi yang baik terhadap seorang dokter, sebagai suatu profesi yang luhur dan memiliki kesuksesan secara finansial. Persepsi merupakan suatu proses penerimaan informasi secara langsung, yang terbentuk dari pengalaman, dan tersimpan dalam memori ${ }^{13}$. Persepsi dipengaruhi oleh beberapa faktor, seperti diantaranya perhatian, kebutuhan, sistem nilai, serta adanya gangguan pada kejiawaan akan menyebabkan berbedanya persepsi yang dibentuk oleh seseorang ${ }^{14}$. Dengan mengetahui bagaimana persepsi mahasiswa tersebut terhadap seorang dokter, baik positif maupun negatif, maka pelaksanaan kurikulum pendidikan dokter dapat disesuaikan sehingga dapat memperkuat persepsi yang positif tersebut.

Data mengenai motivasi maupun persepsi ini selanjutnya dapat dimanfaatkan dalam pengembangan maupun pelaksanaan kurikulum pendidikan dokter. Pendidikan dokter di masa depanmemilikitantanganyanglebihberatterutama dengan perkembangan ilmu dan teknologi yang cepat serta penemuan berbagai penyakit yang baru atau reemerging. Untuk itu pendidikan yang dijalankan harus dapat mendorong mahasiswa yang self-directed learner, memiliki kemampuan untuk memecahkan masalah dan memiliki inovasi dan kreasi. Pendidikan semakin didekatkan pada permasalahan kesehatan di masyarakat sehingga mahasiswa dapat secara langsung mengenal dan memahami tempat kerjanya nanti di masa depan. ${ }^{14,15}$ Dengan proses ini maka motivasi mahasiswa yang dari awal sudah memiliki keinginan untuk terlibat pada pelayanan kesehatan akan tetap berkembang dan mereka bersedia bekerja pada pelayanan kesehatan primer. Hal ini akan dapat mengurangi permasalahan keterbatasan dan maldistribusi dokter pada pelayanan kesehatan primer yang terjadi saat ini.
Pada penelitian ini, jawaban dari mahasiswa tidak dapat dilakukan konfirmasi karena diisi masing-masing dan tidak dilakukan pendalaman lagi (in-depth interview) sehingga tidak diketahui apakah jawaban yang diberikan benar adanya. Selain itu jawaban tersebut tidak diperdalam untuk menggali dasar motivasi dan persepsi yang dimiliki mahasiswa. Penelitian lebih lanjut dapat dilakukan untuk menyelesaikan keterbatasan ini. Selain itu dengan kurikulum pendidikan dokter yang saat ini dilaksanakan perlu dievaluasi apakah motivasi dan persepsi yang telah dimiliki mahasiswa ini akan tetap ada sampai mahasiswa menyelesaikan pendidikannya atau mengalami perubahan.

\section{Daftar Pustaka}

1. Undang-Undang Pendidikan Kedokteran No. 20 Tahun 2013. Jakarta 2013.

2. Covington M. The motive of self-worth. In: Ames REA, C, editor. Motivation in education: student motivation. San Diego: Academic Press; 1984. p. 77-113.

3. Unpad. Laporan Yudisium Tahun Akademik 2013/2014 Bandung: FK Unpad 2014.

4. Kusurkar RA, van Asperen M, Croiset G. Motivation as an independent and a dependent variable in medical education: A review of the literature. Medical Teacher. 2011;33(5).

5. Knowles M. Andragogy in action: applying modern principles of adult learning. San Francisco: Jossey-Bass; 1984.

6. Kusurkar R. Motivation in medical students: a PhD thesis report. Perspect Med Educ University Medical Center, Utrecht, the Netherlands; 2012.

7. Kusurkar RC, van Asperenae M, Croisetbf, G. Motivation as an independent and a dependent variable in medical education: A review of the literature. Medical Teacher. 2011;33:e242-e62.

8. Dornan T, King N, Scherpbier A. Experiencebased learning: A model linking the processes and outcomes of medical students' workplace learning. Medical Education. 2007;41:81-91.

9. RM Ryan ED. Intrinsic and extrinsic motivations: Classic definitions and new directions. Contemp Educ Psychol. 2000;25:54-67.

10. Pedoman Pendidikan Sarjana Kedokteran Fakultas Kedokteran Universitas Padjadjaran. Bandung. 2014.

11. Sobral D. What kind of motivation drives medical students learning quests? Medical Education. 2004;38:950-7.

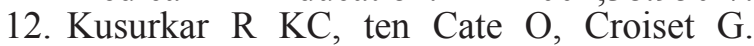


Effects of Age, Gender and Educational Background on Strength of Motivation for Medical School. Advances in Health Sciences Education. 2010;15(3):303-13.

13. Wilkinson TJ. Medical student characteristics associated with time in study: Is spending more time always a good thing? Medical Teacher. 2007;29:106-10.

14. Dornan T, Margolis SA, Scherpbier A, Spencer J, Ypinazar V. How can experience in clinical and community settings contribute to early medical education? A BEME systematic review. Med Teach. 2006;28:3-18. 15. Frenk J CL, Bhutta ZA, et al. Health professionals for a new century: Transforming education to strengthen health systems in an interdependent world. Lancet 2010;376:1923-58. 